\title{
Artificial neural networks based predictive model for worker assignment into virtual cells
}

\author{
${ }^{1 *}$ R.V. Murali, ${ }^{2}$ A.B. Puri and ${ }^{3}$ G. Prabhakaran \\ ${ }^{1}$ Department of Mechanical and Industrial Engineering, Caledonian College of Engineering, PB 2322, CPO Seeb 111, OMAN \\ ${ }^{2}$ Department of Mechanical Engineering, NIT, Durgapur, West Bengal, INDIA \\ ${ }_{3}^{3}$ Department of Mechanical Engineering, Sri Ramachandra Institute of Technology, Chennai, INDIA \\ E-mails: (murali@caledonian.edu.om (R.V. Murali) ${ }^{*}$ Corresponding author; abpuri2000@yahoo.co.in (A.B.Puri); g_prabha2006@yahoo.com (G.Prabhakaran))
}

\begin{abstract}
Virtual cellular manufacturing systems (VCMS) have come into existence, replacing traditional cellular manufacturing systems (CMS), to meet highly dynamic production conditions in terms of demand, processing times, product mix and processing sequence. While cell formation phase of VCMS has been dealt quite voluminously, worker assignments phase has gained momentum recently after researchers started realizing the importance of workers' role during implementation of cell-based manufacturing. In the past, worker assignments have been analyzed with development of various heuristics/mathematical models in order to achieve reduced worker costs, improved productivity and quality, effective utilization of workforce and providing adequate levels of worker flexibility. In this paper, a new approach based on artificial neural networks (ANNs) has been proposed to assign workers into virtual cells since ANNs have the ability to model complex relationships between inputs and outputs and find similar patterns effectively. A framework of multilayered perceptron with feed forward (MLP-FF) neural network has been formulated on worker assignment for VCMS under dual resource constrained (DRC) context and its performance under two cell configurations with different time periods is analyzed. A worker assignment model has been developed and applied with cell formation solutions available in the literature in order to generate simulated datasets that drive the training process of proposed ANN framework.
\end{abstract}

Keywords: Virtual cellular manufacturing, worker assignments, artificial neural networks

\section{Introduction}

The introduction of group technology (GT) into manufacturing environments in late 1950s has revolutionized the art of manufacturing. It has completely changed the traditional way in which operations were carried out in order to respond quickly to changes in product design and demand, resulting in reduced time to make the products, minimum flow time of parts, reduced work-in-process (WIP) inventory and improved product quality. VCMS, stemmed from traditional CMS, is a production methodology where production cells are virtually formed taking machineries and facilities across the shop floor without a necessity of considering the proximity factor. VCMS does not prompt any reconfiguration of the existing layouts in the company while enjoying the benefits associated with traditional CMS (Slomp et al., 2005-a). It is reported that research works on VCMS focused predominantly on machine related sources and issues including material handling aspects while worker related aspects are almost neglected (Slomp et al., 2005-a; Gert Nomden et al., 2006) with a few exceptions (Min and Shin, 1993; Süer, 1996; Askin, and Huang, 2001; Suresh,and Slomp, 2005). Another effort (Suresh and Gerard, 2000) has emphasized the importance of considering workers as a second constraining resource in VCMS environments. Worker assignments into virtual cells require due attention on worker skills and capacities, load distribution, and cross-training needs to sustain cellular operations with adequate levels of worker flexibility (Suresh and Slomp 2001). Among the models developed for worker assignments, heuristics and mathematical formulations take the central role while non-mathematical models such as ANNs are not attempted.

ANNs, a clustering technique principally adapted from the biological nervous systems and neural networks, have a huge potential in solving more complex and nonlinear problems through learning and training. Applications of ANNs have been very 
emergent ranging from manufacturing to telecommunications to financial sectors owing to their proven goodness in approximating functions and recognizing similar patterns. In manufacturing context, cell formation has been an excellent domain for ANNs and there are a number of neural network approaches experimented for cell formation (Kaparthi and Suresh, 1992; Dagli and Huggahalli, 1993).

However, application of ANN concepts on worker assignments in virtual cellular environments could prove potential and efficient since the worker assignments are done under varying, dynamic and stochastic conditions in terms of product demand, product mix and worker skill sets. Therefore, an attempt is made in this paper to formulate an ANN framework for worker assignments into virtual cells and analyze its effectiveness on workers clustering efficiency. It is found out in this study that ANN framework for solving worker assignment models is simpler, more flexible and yet effective, not computationally intensive and can be adapted to varying production conditions.

A major intricacy in employing ANNs technique to any clustering tasks is the need of real training datasets to drive for ANN framework and this might be one of the reasons why ANN approaches were not used for worker assignments. In this attempt, the datasets are derived by preprocessing the information on cell formation such as number of virtual cells, number of machines, jobs and workers, available in the literature. Although this framework does not use real time data from a manufacturing industry, the data abstracted from the literature are already either taken from the real production line or the generated data which are validated and published in the literatures. Hence, authors strongly feel that this approach would also work good and yield acceptable results when a real time data is fed in. Further, this is a novel approach and similar efforts and approaches were not attempted before. Various practical implications and aspects specific to industries can also be added while enriching this model which therefore opens up new avenues for future research.

The worker assignment problem addressed in this work is applicable to manufacturing industries which adopt VCMS concepts in their production line. More information on the principle, scope and applications of virtual cells based manufacturing are found (Nomden et al. 2006; Kannan and Ghosh, 1996) and the details on users with implementation experiences are outlined in Wemmerlov and Johnson (1997).

In the following section, various research works carried out on worker assignment problems in cell based manufacturing environments are presented and grounds for the present study are also explained. Then, based on the ANN concepts, a framework for this study is proposed. Problem formulation and ANN training architecture/training parameters are given thereafter. Results obtained by this attempt for the datasets available in the literature are presented later which is followed by a short discussion. Finally, conclusion remarks are given with appropriate future works identified.

\section{Literature review and background}

In all manufacturing methodology being adopted for production, worker assignment has positioned itself strongly due to a fact that work force is a major constraining resource in a manufacturing organization. However, workforce issue is handled heuristically by matching the technical skills of the workers with production requirements. Most worker assignments are made based on the experience of the personnel involved with the cells. Many times, particularly at the cell implementation level, work force decisions involve a lot of trial and error and therefore, companies do not make the best use of their worker and machine resources (Viviana and Harold, 2005). It is also indicated that in cell based manufacturing, many of the perceived advantages are derived from holding sufficient levels of worker flexibility within each cell (Slomp et al., 2005-a; Slomp et al., 2005-b).

In this context, a multi-objective mathematical model was framed (Min and Shin, 1993) in an effort to perform simultaneous formation of machine and human manufacturing cells on the basis of skill match. One of the shortcomings of this approach was that the data analyzed are hypothetical and skill levels were static. The paper (Süer, 1996) proposed a two-phase hierarchical methodology in order to achieve an optimal manpower assignment. In this paper, mixed integer and integer programming formulations are proposed to generate alternative operator levels and to achieve the optimal operator and product assignment to the cells. Eventually as an extension of this work in (Süer and Ivan, 1997) mathematical models are developed to generate alternative operator levels and to obtain the optimal common operator and product assignment to the cells. This work was extended for analyzing the impact of lot-splitting in terms of setup times (Süer, 1998).

Two integer programming models were developed in the paper (Askin and Huang, 1997) for assigning workers to cells and determining an appropriate training programme schedule for employees. A major assumption made in this model was that each different skill has only one level rather than multiple levels for each skill. They later extended their own work to examine not only the formation of worker teams, also the specification of cross-training plans for workers in cellular design (Askin and Huang, 2001). In this work, the worker skill level was considered to be a binary variable i.e., 1 if the worker possesses the skill; 0 otherwise.

Another effort in (Bryan et al., 2002) established that the worker assignments have been traditionally based on only the technical skills of the workers, not other abilities. Subsequently, they proposed a mixed integer programming model that showed a significant improvement in cell performance when human skills were explicitly considered in the worker training plan and assignment strategies. Kannan and Jensen (2004) have demonstrated that labour resource with its dynamics in terms of operator performance in studies of manufacturing cells can change the outcome drastically. The Authors (Bopaya et al., 2005) have indicated that although cell based manufacturing results in productive benefits and forms the central theme of research for 
researchers, yet, the importance of human issues is never dealt in full and further there is a singular absence of articles in relation to human element in cellular manufacturing. It is also emphasized that the lack of understanding of the human side of cellular manufacturing could significantly reduce the benefits associated with this mode of manufacturing. Later, goal programming model was derived (Slomp et al., 2005-a) for a virtual cellular design framework to form virtual cells initially and then to assign workers to these virtual cells. This work was further developed and analyzed (Murali R V et al., 2009) considering the empirical aspects related to worker assignments such as job criticality and varied worker efficiency in VCMS environments through a binary integer programming model.

Thompson and Goodale (2006) have reaffirmed that ignoring the worker as a source of variability leads to significant errors in projecting output of the company and included this aspect into their work on scheduling workforce. Fowler et al., (2008) have concluded that workforce management is done with a help of a measure called general cognitive ability (GCA) because each worker is inherently different. Recently, McDonald et al., (2009) have developed a worker assignment mathematical model for lean manufacturing cells to ensure job rotation and determine the levels of skill and training necessary to meet customer demand. The objective of this model is to minimize net present cost, which includes initial training costs, incremental training costs necessary to complete tasks and meet customer demand, inventory costs, and cost of poor quality. Another study by Davis et al., (2009) contents that workload imbalances give rise to worker flexibility and current work center capacity influences the extent to which worker flexibility can be utilized to counter the workload imbalances.

It is observed in all these papers presented above that various heuristics, mathematical formulations were developed for solving worker assignment problems applicable to cell-based manufacturing environments. Although ANN clustering technique was very widely applied for cell formation problems during this period, no attempt is made to apply this technique to worker assignment phase. Further, ANN techniques require significantly less storage and processing time than conventional approaches. As the complexity of the problem increases in terms of the cell size and resources, it becomes computationally expensive if conventional approaches are employed.

Authors have, therefore, attempted to handle the worker assignment task applicable to VCMS environment in the DRC context for different time periods using ANNs with simulated datasets in this approach. This paper derives a worker assignment model that determines the fitness attributes of each worker for each cell in terms of machine coverage ratio, multi-functionality and the total processing time, considering the cell formation solutions available in the literature.

\section{Neural network classifier scheme}

ANNs strive to behave in a much similar way as the brain of human beings and they are deemed to perform tasks through gaining knowledge obtained by learning or training process. More precisely, ANNs have the ability to learn from experience, adapt to new situations, and provide reliable classifications and approximations of data through input-output mapping and adaptive characteristics. It consists of processing units called artificial neurons or nodes which receive an input data, processes it, and produces an output that acts as an input to other nodes in the network ie., inter-connection of simple processing elements. The connections among the nodes and various learning algorithms to alter the weight factors between the connecting nodes are ANN's strength and flexibility as well. The behavior of network can be altered by suitably selecting the appropriate transfer functions for each layer which takes the input arguments and processes them according to the transfer function selected and produces the desired output. Most common transfer functions used for the hidden layer is tansig and the output layer is pure linear. (Haykin, 1999)

Supervised or unsupervised are the two major types of neural networks that find wider acceptance and use among the researchers. Supervised networks will essentially function based on the training sets i.e. valid and relevant input/output values to train the network and adjust the connection weights between the individual nodes. In recent times, unsupervised neural networks are preferred owing to a fact that they have the ability to adapt and classify the input data without needing input/output values for training. In this problem, supervised neural networks i.e., feed forward network is employed with use of simulated training datasets derived from the proposed worker assignment model.

\subsection{Multi-layer perceptrons feed forward (MLP-FF) networks}

MLP-FF networks are one of the important types of supervised neural networks that consist of more hidden layers besides input and output layer. In this attempt, authors propose to use a MLP-FF network with one hidden layer (with tansig transfer function and 3 hidden neurons) for workers assignment.

From the generalized block diagram of MLP shown in the Figure 1, the output of each layer (i) is calculated using (1):

$$
\text { Output }_{i}=\text { Sout }_{i-1}-w_{i-1, i}
$$

Where out $t_{i}$ and $w_{\mathrm{i}-1, i}$ are the output of the layer $i$ and weight factor values of the data flow from layer $i-1$ to layer $i$. 


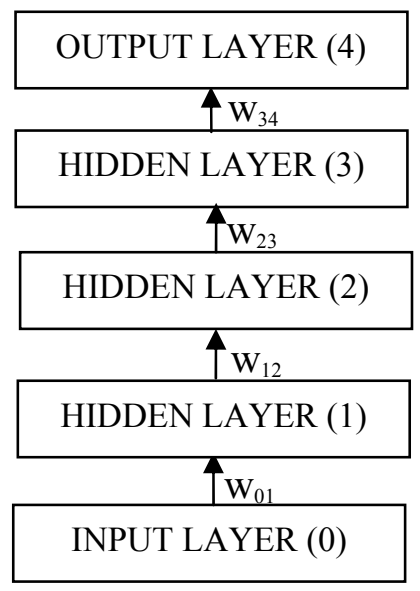

Figure 1 Generalized block diagram of MLP

In the proposed work, 6 input variables (P1-P6) are fed into the input layer, which are processed by 3 neurons of the hidden layer $\left(h_{1}, h_{2}\right.$ and $\left.h_{3}\right)$ with appropriate initial weight factors. Upon processing, it will yield 3 output variables $\left(\mathrm{C}_{1}, \mathrm{C}_{2}\right.$ and $\left.\mathrm{C}_{1,2}\right)$ in the output layer where they are compared with the desired target output (detailed explanation given in the problem framework phase). The error $\left(\Delta=\beta_{\text {actual }}-\beta_{\text {target }}\right)$ is back propagated through the network where the individual weights are adjusted to bring the output closer to the target value. This process is termed as network training or learning.

There are many training algorithms such as traingdm, levenberg-marquardt available for use in ANN models The choice of selecting training algorithms will be done on the basis of many aspects such as the complexity of the problem, the number of input/output variables, number of training datasets, the number of weights and biases in the network, the error values and purpose of the network (pattern recognition/function approximation). During training process, the weight factors of the network are iteratively adjusted to minimize the performance error values (mean squared error- MSE) between the actual outputs and the desired (target) outputs. This framework uses Gradient Descent with Momentum (traingdm) algorithm for training with tansig and purelin as transfer functions used for hidden and output layers. This algorithm needs two training parameters namely the learning rate (LR) and the momentum constant (MC). The LR is multiplied times the negative of the gradient to determine the changes to the weight factors. The higher the values of LR, the bigger the step size towards achieving the target. If the LR is set to a very higher value, the learning process will not be useful. On the other hand, setting very small values to LR will take more time to stabilize. MC defines the sensitivity of the network to changes and allows the network to ignore small features in the error surface. Its values range between 0 (no momentum) and close to 1 (lots of momentum). A MC value of 1 results in a network that is completely insensitive to the local gradient and, therefore, does not lead to a proper learning. The back propagation learning phase of the network updates the network weight factors in such a way that performance errors decrease most rapidly i.e. the high degree of closeness is achieved between the actual outputs and the desired (target) outputs as given by (2):

$$
\Delta_{\mathrm{i}+1}=\Delta_{\mathrm{i}}-(\mathrm{LR} . \delta)
$$

where $\Delta_{\mathrm{i}}$ is a current input variable and $\delta$ is the current gradient. The architecture and training parameters of the proposed ANN framework is shown in the Figure 2.

Accuracy of the ANN classifications could be enhanced if the initial network weight factors are reset to appropriate values and a fresh training can be given. Increasing the number of hidden neurons, training datasets, input vectors and finally choosing a suitable training algorithm will also result in improvements.

\section{Problem formulation and parameters for the ANN framework}

The key difference between cellular and virtual cellular manufacturing systems is the need of reconfiguration of the machines and layouts. In cellular manufacturing, machines are brought closer to form cells while VCMS does not impose upon this. Mere dedication of identified machines across various departments in the form of logical groups will suffice for creating virtual cells. For every time period, member machines of this logical group will change based on the demand, products, product mix and production sequence.

Therefore, in this paper, traditional cell formation solutions adapted from literature are treated as applicable to virtual cellular environments i.e., for each period, datasets with different production time and sequence are considered which is equivalent to working on virtual cell formation problems and data.

The conceptual diagram of the proposed work (worker assignment model plus ANN framework) is illustrated in the Figure 3. Initially, from literature, cell formation solutions such as number of cells formed, parts and machines allotted to each cell, 
processing times, number of exceptional elements with production details and sequence for each part are extracted. These details are preprocessed and transformed into worker fitness attributes as discussed in the following section. Table 1 lists down various referred literature problems with sizes (for two cell configuration) to be adapted in this paper for generating training datasets and testing ANN framework as well.

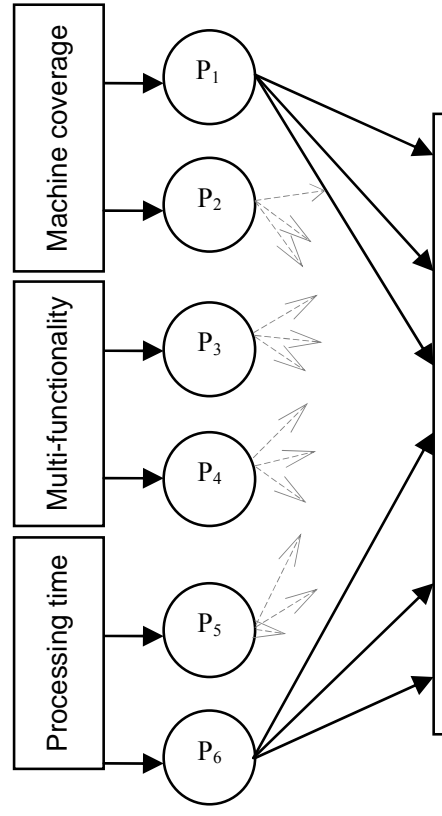

\begin{tabular}{|l|l|}
\hline \multicolumn{2}{|c|}{ ANN Training Parameters } \\
\hline Training Algorithm & $\begin{array}{l}\text { Descent Gradient with Moment } \\
\text { (TRAINGDM) }\end{array}$ \\
\hline LR & 0.3 \\
\hline $\begin{array}{l}\text { MC value for stabilizing } \\
\text { the network }\end{array}$ & 0.6 \\
\hline $\begin{array}{l}\text { Error function } \\
\text { Mean Squared Error (MSE) } \\
\text { value=0.1 }\end{array}$ \\
\hline Max no. of epochs & 1000 \\
\hline No of neurons & 6 inputs; 3 hidden; 3 outputs \\
\hline
\end{tabular}

Figure $2 \mathrm{ANN}$ architecture and training parameters

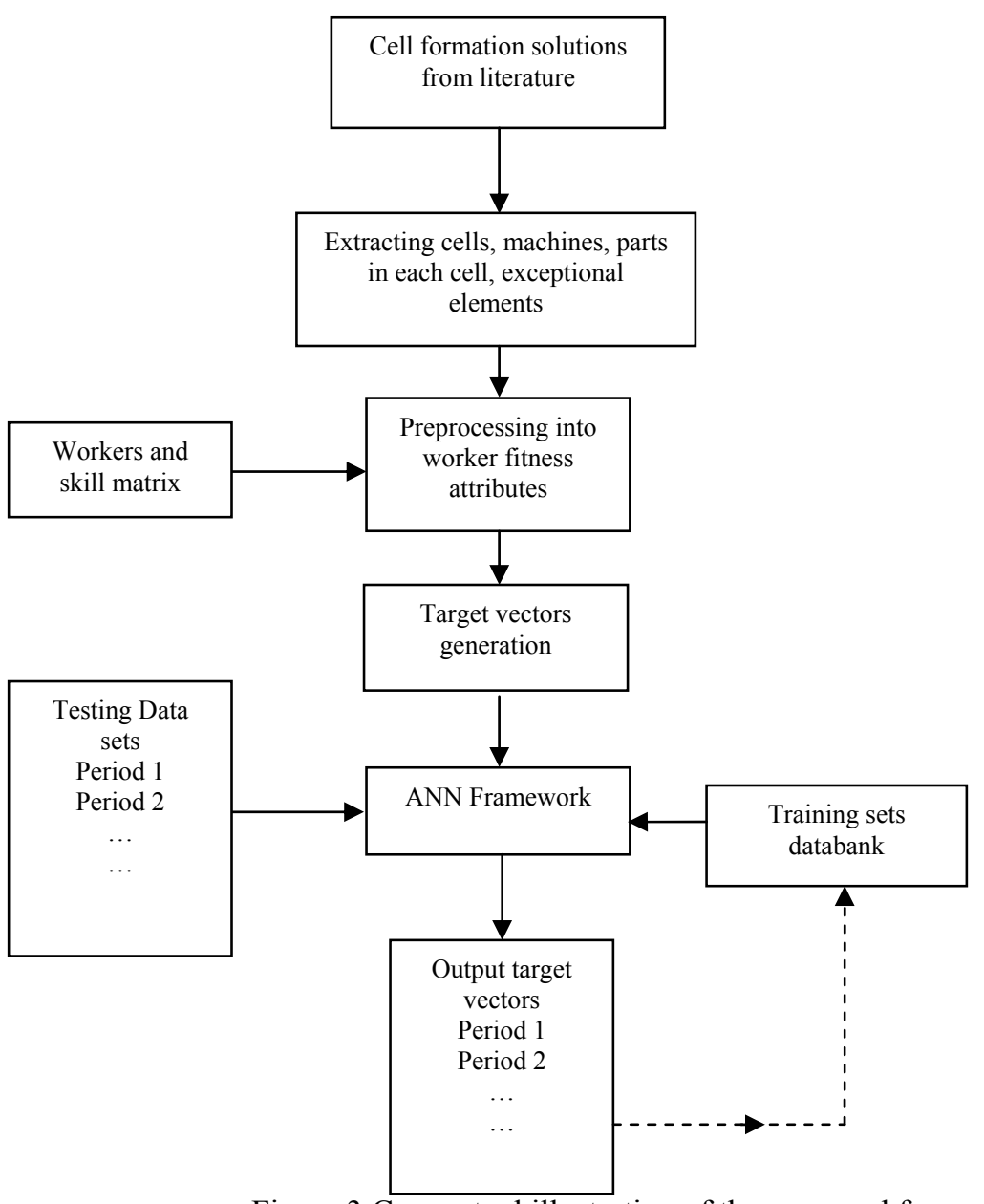

Figure 3 Conceptual illustration of the proposed framework 
Table 1 Test problems for training and testing ANN with sizes and sources*

\begin{tabular}{|c|c|c|c|}
\hline & $\begin{array}{l}\text { Dataset } \\
\text { No }\end{array}$ & Literature Source & $\begin{array}{l}\text { Problem Size } \\
\text { (Machine x Parts) }\end{array}$ \\
\hline \multirow{6}{*}{ 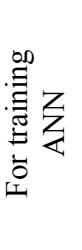 } & 1 & King and Nakornchai (1982) & $5 \times 7$ \\
\hline & 2 & Waghodekar and sahu (1984) & $5 \times 7$ \\
\hline & 3 & Seiffodini (1989) & $5 \times 18$ \\
\hline & 4 & Chandrasekaran et al. (1986)b & $8 \times 20$ \\
\hline & 5 & Generated Set 1 & - \\
\hline & 6 & Generated Set 2 & - \\
\hline \multirow{3}{*}{ 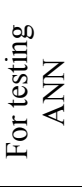 } & 7 & Kusiak (1992) & $6 \times 8$ \\
\hline & 8 & $\begin{array}{l}\text { Sudhakara and Mahapatra } \\
(2009)\end{array}$ & $5 \times 7$ \\
\hline & 9 & $\begin{array}{l}\text { Sudhakara and Mahapatra } \\
\text { (2009) }\end{array}$ & $6 \times 8$ \\
\hline
\end{tabular}

\subsection{Fitness attributes}

Authors strongly advocate that worker assignment into cells should be based on what extent a worker adds value to a particular cell in terms of fitness attributes such as machine coverage ratio, multi-functionality and total processing load. If he/she does not contribute value to a particular cell, his/her fitness for this cell would be lower and hence not preferred to be assigned into this cell. However, when values of all these fitness attributes for the virtual cells under discussion tie or match or run closer, it leads to a condition that this particular worker is fit to be allotted to both cells.

4.1.1 Machine coverage ratio

In the literature (Slomp et al., 2005-a) machine coverage of machines is defined as the number of operators capable of operating each machine. In this context machine coverage ratio of operators is referred to be a ratio of the number of machines he/she is eligible to operate in a cell to the total number of machines assigned to the particular cell. Higher values of this parameter imply that he/she is qualified to process more parts in that particular cell. Therefore, it is contended when a worker attains higher values of machine coverage ratio in a virtual cell, he/she is preferred to be assigned to that virtual cell.

4.1.2 Multi-functionality

Multi-functionality of a worker is defined (Slomp et al., 2005-a; 2005-b) as number of machine types that each worker can operate. In this context, authors propose to consider multi-functionality as an index referring to the total number of operations he/she is eligible to perform on different machines in a particular cell he/she is considered for assignment. This index is deemed to measure the ability of a worker to process a number of operations in a virtual cell. When a worker is able to perform more number of operations on different parts in a particular cell, then he/she will secure higher fitness values for assignment into this virtual cell. 4.1.3 Total processing time

In addition to the number of machines and number of operations a worker is eligible to process in a cell, total processing time for all operations each worker is eligible to process, would also have to be accounted for exercising assignment task. Therefore, it is proposed to include this factor as one of the fitness attributes in this work.

\subsection{Performance measures}

Worker utilization, machine utilization and cell load are some of the performance measures estimated for the assignment achieved by the proposed ANN framework. Also, Worker Flexibility Index and Cross Training Index are redefined and analyzed for the results achieved in this work.

\subsubsection{Worker Flexibility Index}

Worker flexibility in the context of cell based manufacturing relates to the multiple skills of workers and their ability to work in teams so that greater number of tasks can be assigned to them. Workers allocation to machines shall be so carried out that the fluctuations in demand, fluctuations in worker supply, worker absenteeism are accounted for ensuring smooth production process (Bryan et al., 2002). It is outlined (Slomp et al., 2005-b) that worker flexibility could be interpreted as the probability of having workers who are fully loaded while simultaneously having underutilized workers. In this attempt, authors have defined worker flexibility as the $\%$ of total number of operations in a cell that can be undertaken by minimum of two workers or more so that worker flexibility is established.

$$
\text { Worker flexibility index for cell, } F_{w i}=\frac{\sum_{\perp}^{n} X_{i j}}{n}
$$

Where $X_{i j}=1$, if a job $j$ assigned to cell $i$ can be processed by minimum of two workers belonging to cell $i$; 0 otherwise $\mathrm{n}=$ total no of jobs assigned to cell $\mathrm{i}$. The range of $\mathrm{F}_{\mathrm{wi}}$ is from 0 to 1 i.e., from no flexibility to highly flexible.

4.2.2 Cross Training Index 
Worker flexibility and cross training are complementing each other. Higher values of worker flexibility will mean that there are enough workforces available to handle extreme situations so that there cross training needs are minimized. Hence, cross training index can be given as follows:

$$
\text { Cross Training Index, } C T_{i}=1-F W_{i}
$$

The range of $C T_{i}$ is from 0 to 1 i.e., from minimum cross training needs to maximum cross training needs to be provided to workers on the basis of their work load and cell load values.

Based on the values of fitness attributes of each worker, workers assignment is completed for totally 6 problems as indicated in Table 1 and eventually training datasets are prepared. Table 2 gives the cell formation solutions and production details for dataset 1 (King and Nakornchai, 1982).

Table 2 (a) Machine Part Incidence Matrix (b) Cell formation solutions (c) Worker skill matrix

\begin{tabular}{|c|c|c|c|c|c|c|c|c|}
\hline & \multicolumn{7}{|c|}{ Parts } \\
\hline & & P1 & $\mathrm{P} 2$ & P3 & P4 & $\mathrm{P} 5$ & P6 & P7 \\
\hline \multirow{5}{*}{ 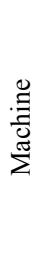 } & M1 & 0.00 & 0.53 & 0.00 & 0.99 & 0.83 & 0.91 & 0.00 \\
\hline & M2 & 0.82 & 0.00 & 0.83 & 0.00 & 0.00 & 0.00 & 0.00 \\
\hline & M3 & 0.91 & 0.00 & 0.92 & 0.00 & 0.00 & 0.86 & 0.97 \\
\hline & M4 & 0.00 & 0.79 & 0.00 & 0.56 & 0.00 & 0.88 & 0.00 \\
\hline & M5 & 0.53 & 0.00 & 0.00 & 0.00 & 0.51 & 0.00 & 0.98 \\
\hline
\end{tabular}

\begin{tabular}{|l|l|l|}
\hline \multirow{2}{*}{ Machines in } & Cell 1 & M2, M3, M5 \\
\cline { 2 - 3 } & Cell 2 & M1, M4 \\
\hline \multirow{2}{*}{ Parts in } & Cell 1 & P1, P3, P7 \\
\cline { 2 - 3 } & Cell 2 & P2, P4, P5, P6 \\
\hline No of workers & 4 \\
\hline
\end{tabular}

(b)

\begin{tabular}{|c|c|c|c|c|c|c|}
\hline & \multicolumn{5}{|c|}{ Machine } \\
\hline & & M1 & M2 & M3 & M4 & M5 \\
\hline \multirow{4}{*}{ 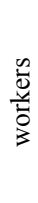 } & W1 & 1 & 1 & 0 & 0 & 1 \\
\hline & W2 & 1 & 0 & 1 & 1 & 0 \\
\hline & W3 & 0 & 1 & 1 & 0 & 1 \\
\hline & W4 & 0 & 1 & 0 & 1 & 1 \\
\hline
\end{tabular}

(c)

Table 3 lists down the sample training data for ANN framework pertaining to literature problems obtained through the proposed worker assignment model. The ANN output target nodes are denoted as 3 digit numbers which reflect the classification scheme for workers. Cell 1 and Cell 2 are indicated by $\left\{\begin{array}{lll}1 & 0 & 0\end{array}\right\}$ and $\left\{\begin{array}{lll}0 & 1 & 0\end{array}\right\}$ respectively while worker assignments to both cells are mapped to representation scheme $\left\{\begin{array}{lll}0 & 0 & 1\end{array}\right\}$. It should be noted that this workout assumes a certain number of workers with their skills and a particular demand situation (virtual cell formation period is assumed as one month) to cope with variations in the demand mix and fluctuations in the workforce availability. The number of workers is so chosen considering the DRC contexts in which the number of workers available is less than the number of machines (Viviana and Harold, 2005; Jensen, 2000).

\section{Simulation test results and discussion}

The proposed ANN framework is tested with cell formation solutions taken from the literature and the results are enclosed in this section. From Table 1, it is noted that datasets for four literature problems (datasets 1-4) and two indigenously generated datasets (datasets 5-6) were used for ANN training while for testing ANN framework, three literature problems (datasets 7-9) are used as inputs for different periods of VCMS. Tables 4 and 5 show the simulation test results and performance measures calculated from the results.

The summary of the results can be given as follows:

1. For the period 1, the worker assignments are deemed satisfactory since worker load distribution is uniform. However, machine M2 is overloaded because of the fact that out of 8 parts, 7 parts require processing on it. The actual utilization of machine M2 and total load for cell 2 exceed $100 \%$. It is thus recommended to hire an additional machine M2 to ensure balanced worker loads and cell loads. On implementing this recommendation, utilization value of machine M2 has dropped to $56 \%$ and cell load has reached $60 \%$. Workers' flexibility index is low (0.27) for cell 1 while it has reached maximum value (ie., 1$)$ for cell 2 
needing no cross training at all. Medium to high levels of cross training programmes are to be planned for cell 1 during this period for achieving higher flexibility and balanced worker load.

Table 3 Sample training data for ANN framework

\begin{tabular}{|c|c|c|c|c|c|c|c|c|c|c|}
\hline \multirow{3}{*}{$\begin{array}{l}\text { Dataset } \\
\text { No }\end{array}$} & \multirow{3}{*}{ Workers } & \multicolumn{6}{|c|}{ Worker Fitness Attributes (6 input variables) } & \multirow{3}{*}{\multicolumn{3}{|c|}{$\begin{array}{c}\text { Desired } \\
\text { Target } \\
\text { Vectors } \\
\text { (3 output } \\
\text { variables) }\end{array}$}} \\
\hline & & \multicolumn{2}{|c|}{$\begin{array}{l}\text { Machine coverage } \\
\text { ratio of each } \\
\text { worker in }\end{array}$} & \multicolumn{2}{|c|}{$\begin{array}{l}\text { Multi-functionality } \\
\text { of each worker in }\end{array}$} & \multicolumn{2}{|c|}{$\begin{array}{l}\text { Total processing } \\
\text { (hr) load in }\end{array}$} & & & \\
\hline & & Cell 1 & Cell 2 & Cell 1 & Cell 2 & Cell 1 & Cell 2 & & & \\
\hline \multirow{4}{*}{1} & W1 & 0.667 & 0.5 & 4 & 4 & 3.38 & 2.92 & 0 & 0 & 1 \\
\hline & W2 & 0.333 & 1 & 3 & 7 & 1.37 & 4.12 & 0 & 1 & 0 \\
\hline & W3 & 1 & 0 & 7 & 0 & 4.75 & 0 & 1 & 0 & 0 \\
\hline & W4 & 0.667 & 0.5 & 4 & 3 & 3.38 & 1.2 & 1 & 0 & 0 \\
\hline \multirow{4}{*}{2} & W1 & 0.5 & 0.667 & 2 & 7 & 1.53 & 3.54 & 0 & 1 & 0 \\
\hline & W2 & 1 & 0.333 & 3 & 4 & 2.03 & 1.31 & 1 & 0 & 0 \\
\hline & W3 & 0 & 1 & 0 & 11 & 0 & 4.85 & 0 & 1 & $\underline{0}$ \\
\hline & W4 & 0.5 & 0.667 & 1 & 7 & 0.5 & 3.54 & 0 & 1 & 0 \\
\hline \multirow{4}{*}{3} & W1 & 0667 & 05 & 10 & 12 & 573 & 764 & 0 & 1 & 0 \\
\hline & W2 & 0.333 & 1 & 5 & 24 & 2.4 & 14.93 & 0 & 1 & 0 \\
\hline & W3 & 1 & 0 & 15 & 0 & 8.13 & 0 & 1 & 0 & $\underline{0}$ \\
\hline & W4 & 0.667 & 0.5 & 10 & 12 & 5.73 & 7.29 & 0 & 0 & 1 \\
\hline \multirow{7}{*}{4} & W1 & 0.333 & 0.4 & 6 & 14 & 2.86 & 9.18 & 0 & 1 & 0 \\
\hline & W2 & 0.333 & 0.4 & 9 & 16 & 5.41 & 8.7 & 0 & 1 & 0 \\
\hline & W3 & 0.667 & 0.4 & 18 & 14 & 8.9 & 7.18 & 1 & 0 & 0 \\
\hline & W4 & 0.333 & 0.4 & 6 & 16 & 2.86 & 7.67 & 0 & 1 & 0 \\
\hline & W5 & 0 & 0.4 & 0 & 16 & 0 & 8.7 & 0 & 1 & $\underline{0}$ \\
\hline & W6 & 0.333 & 0.4 & 9 & 14 & 3.49 & 8.15 & 0 & 1 & $\underline{0}$ \\
\hline & W7 & 0.667 & 0.2 & 15 & 8 & 8.27 & 4.25 & 1 & 0 & 0 \\
\hline
\end{tabular}

2. For the period 2, worker load distribution shows signs of variations with one bottleneck worker identified (W1) because of dual cell assignment. Worker flexibility for cell 1 is low (0.15) necessitating medium to high amounts of cross training. Fairly good amount of flexibility $(0.64)$ is seen in cell 2 needing low to medium levels of cross training.

3. Situation prevailed in period 1 which is recurring in this period with machine M 2 overloaded since 7 out of 8 parts needed it. The actual utilization of machine M2 nearing $90 \%$ and therefore total load for cell 2 exceeds $75 \%$. It is thus recommended to hire an additional machine M2 so that the machine M2 utilization value has dropped to $37 \%$ and cell load has reached $48 \%$. Worker flexibility index for cell 1 registers low prompting a high levels of cross training and cell 2 shows balanced condition between workers flexibility $(0.46)$ and cross training levels $(0.54)$ needing no remedial actions.

Although, the accuracy and performance can be improved by altering the process parameters such as training algorithm, learning rate, the momentum constant and mean square error values, the major factor that dictates its performance is the validity and accuracy of the training data which plays a crucial role in applying neural network techniques. MLP-FF framework is created, designed, developed and tested in MATLAB 2007 software with Intel Pentium-4 processor with $3 \mathrm{GHz}$ speed.

The proposed structure of a MLP-FF network uses six input variables to the input layer, 1 hidden layer with 3 neurons with tansig transfer function and 3 output variables. Figure 4 shows performance curves of the proposed MLP-FF network for different VCMS periods. The number of epochs i.e. the number of iterations the network undergoes by adjusting neuron weights to achieve the intended performance goal is shown against the MSE values in this figure. MSE, a network performance function used in this work, measures the differences between the target and the actual neural network output, squaring them and averaging over all classes and internal validation samples. Training of each ANN is stopped when the prediction error value between two successive iterations reaches MSE value. It is observed from these curves that the number of epochs is more in two periods which implies that the average training time taken by the network is larger. MLP-FF network generally takes larger training time since it involves more training parameters such as LR, MC and so on. This is a drawback of MLP-FF network as reported in the literature (James and David, 1991; Haykin, 1999). 
Table 4 ANN Testing Results

\begin{tabular}{|c|c|c|c|c|c|c|c|c|c|c|c|c|}
\hline \multirow{3}{*}{ 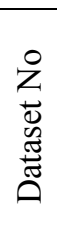 } & \multirow{3}{*}{ 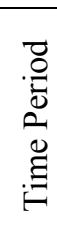 } & \multirow{3}{*}{ Workers } & \multicolumn{6}{|c|}{ WORKER FITNESS ATTRIBUTES } & \multirow{3}{*}{\multicolumn{3}{|c|}{$\begin{array}{c}\text { Target } \\
\text { Vectors } \\
\text { achieved }\end{array}$}} & \multirow{3}{*}{$\begin{array}{l}\text { Worker } \\
\text { Load }\end{array}$} \\
\hline & & & \multicolumn{2}{|c|}{$\begin{array}{l}\text { machine coverage } \\
\text { ratio of each } \\
\text { worker in }\end{array}$} & \multicolumn{2}{|c|}{$\begin{array}{l}\text { Multi-functionality } \\
\text { of each worker in }\end{array}$} & \multicolumn{2}{|c|}{$\begin{array}{l}\text { Total processing } \\
\text { (min) load in }\end{array}$} & & & & \\
\hline & & & Cell 1 & Cell 2 & Cell 1 & Cell 2 & Cell 1 & Cell 2 & & & & \\
\hline \multirow{5}{*}{ - } & \multirow{5}{*}{ 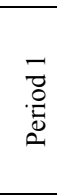 } & W1 & 0.25 & 1 & 2 & 7 & 1.83 & 6.71 & 0 & 1 & 0 & $60 \%$ \\
\hline & & W2 & 0.75 & 0 & 6 & 0 & 5.24 & 0 & 1 & 0 & 0 & $62 \%$ \\
\hline & & W3 & 0.5 & 0.5 & 4 & 4 & 3.41 & 3.73 & 0 & 1 & 0 & $70 \%$ \\
\hline & & W4 & 0.5 & 0.5 & 4 & 3 & 3.25 & 2.98 & 0 & 0 & 1 & $65 \%$ \\
\hline & & W5 & 0.5 & 0 & 4 & 0 & 3.57 & 0 & 1 & 0 & 0 & $55 \%$ \\
\hline \multirow{4}{*}{$\infty$} & & W1 & 1 & 0667 & 7 & 5 & 300 & 370 & 0 & 0 & 1 & $00^{\circ}$ \\
\hline & \multirow{3}{*}{ 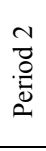 } & W2 & 0.5 & 0.333 & 3 & 2 & 1.14 & 1.57 & 0 & 0 & 1 & $51 \%$ \\
\hline & & W3 & 0.5 & 0.333 & 3 & 3 & 1.14 & 2.22 & 0 & 1 & 0 & $67 \%$ \\
\hline & & W4 & 0.5 & 0.333 & 4 & 3 & 2.85 & 1.99 & 0 & 1 & 0 & $83 \%$ \\
\hline \multirow{5}{*}{$a$} & & & 0333 & 0667 & & 11 & 183 & 088 & 0 & 1 & 0 & $70 \%$ \\
\hline & \multirow{4}{*}{ 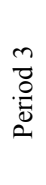 } & W2 & 0.667 & 0.333 & 4 & 3 & $\begin{array}{l}1.05 \\
3.57\end{array}$ & $\begin{array}{l}9.00 \\
2.67\end{array}$ & $\frac{0}{1}$ & $\frac{1}{0}$ & 0 & $20 \%$ \\
\hline & & W3 & 0.333 & 0.667 & 2 & 9 & 1.74 & 8.2 & 0 & 1 & 0 & $71 \%$ \\
\hline & & W4 & 0.667 & 0.333 & 4 & 5 & 3.25 & 4.35 & 1 & 0 & 0 & $16 \%$ \\
\hline & & W5 & 0.667 & 0 & 4 & 0 & 3.57 & 0 & 1 & 0 & 0 & $34 \%$ \\
\hline
\end{tabular}

Table 5 Performance Measures - Results

\begin{tabular}{|c|c|c|c|c|}
\hline \multirow{2}{*}{$\begin{array}{l}\text { PERFORMANCE } \\
\text { MEASURES }\end{array}$} & \multirow{2}{*}{$\begin{array}{l}\text { CELL } \\
\text { NO }\end{array}$} & \multicolumn{3}{|c|}{ TIME PERIOD } \\
\hline & & PERIOD 1 & PERIOD 2 & PERIOD 3 \\
\hline \multirow{2}{*}{ Cell Load } & 1 & $31 \%$ & $51 \%$ & $24 \%$ \\
\hline & 2 & $60 \%{ }^{*}$ & $57 \%$ & $48 \%{ }^{*}$ \\
\hline \multirow{7}{*}{ Machine Utilization } & \multirow{4}{*}{1} & $38 \%$ & $22 \%$ & $35 \%$ \\
\hline & & $53 \%$ & $79 \%$ & $16 \%$ \\
\hline & & $15 \%$ & & $20 \%$ \\
\hline & & M6 $18 \%$ & & \\
\hline & \multirow{3}{*}{2} & \multirow{3}{*}{$\begin{array}{ll}\text { M2 } & 56 \%{ }^{*} \\
\text { M5 } & 68 \%\end{array}$} & $43 \%$ & M2 $37 \%^{*}$ \\
\hline & & & $57 \%$ & $28 \%$ \\
\hline & & & $70 \%$ & $40 \%$ \\
\hline \multirow{2}{*}{ Workers' Flexibility Index } & 1 & 0.27 & 0.15 & 0.24 \\
\hline & 2 & \multirow{2}{*}{1} & 0.64 & 0.46 \\
\hline \multirow{2}{*}{ Cross Training Needs Index } & 1 & & \multirow{2}{*}{0.85} & 0.76 \\
\hline & 2 & $\frac{0.73}{0}$ & & 0.54 \\
\hline
\end{tabular}

* - reworked due to excessive load values 

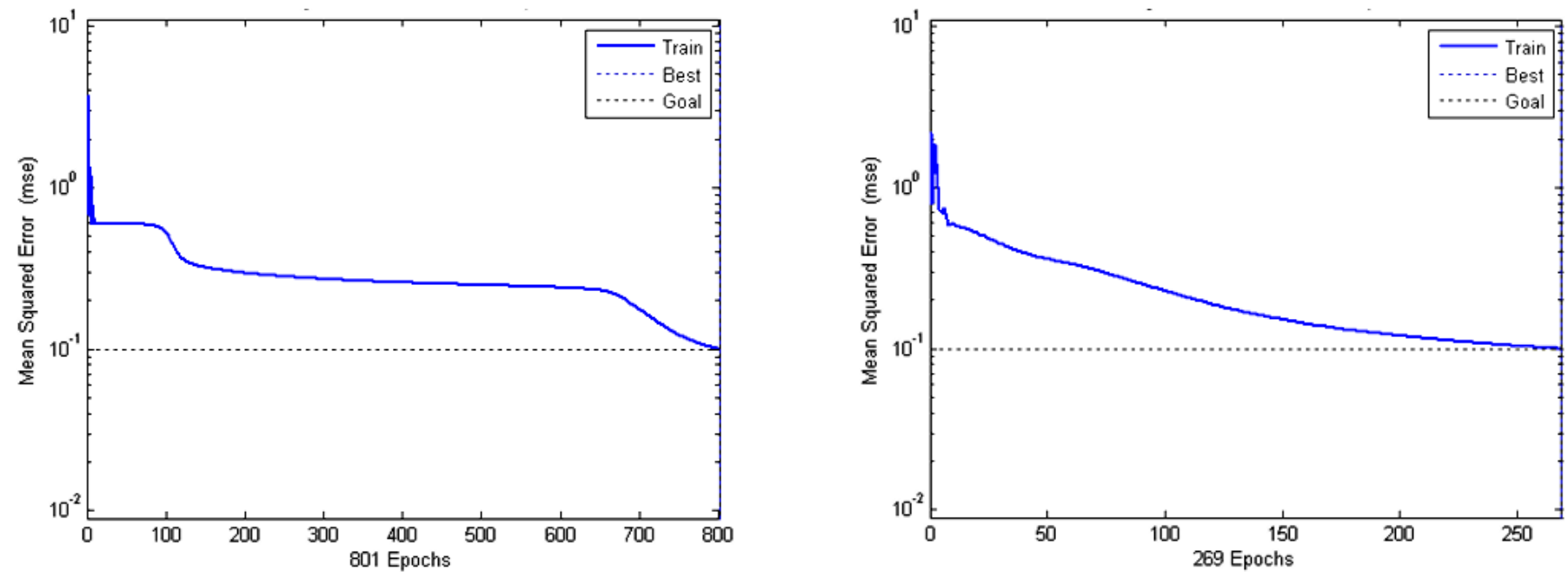

Period 1

Period 2

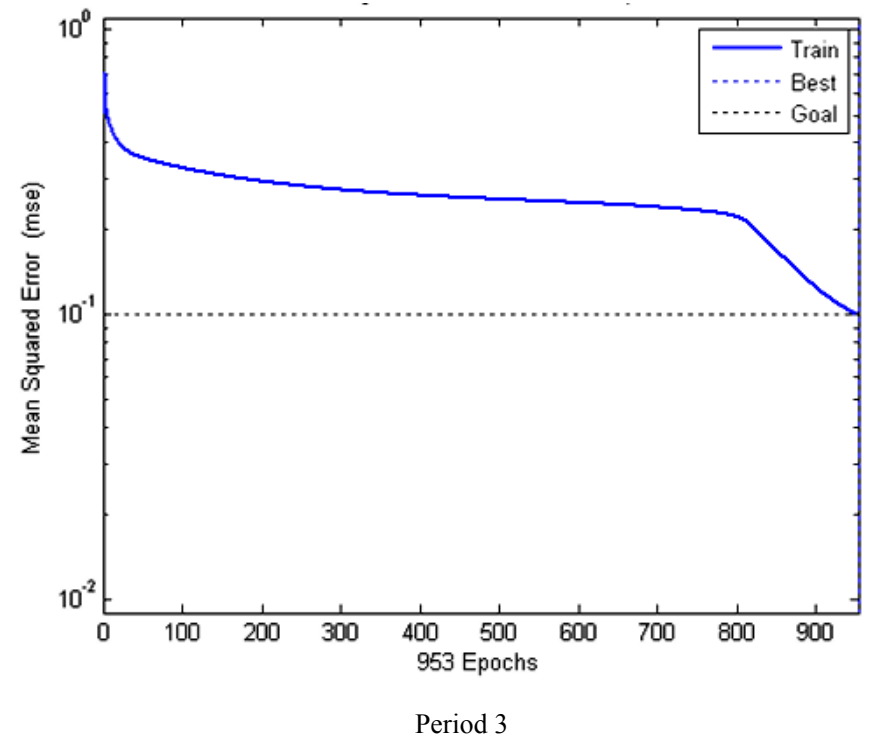

Figure 4 Performance Curves of ANN - Periods 1, 2 \& 3

\section{Conclusions, limitations and future works}

A new ANN approach, a MLP-FF framework, for assigning workers into virtual cells has been proposed in this paper. This simulated ANN model has been driven by cell formation solutions of two cell configurations adapted from the literature. The results obtained through this scheme are examined, critically analyzed via performance measures, summarized and presented in this study. This attempt discovered that the predictive ANN model is able to classify workers into virtual cells successfully and further, with relevant information as input vectors, it would be able to assign workers into virtual cells for any number of time periods or every time when new cells are logically formed.

However, this model, operating on data abstracted from VCMS literature, did not take the real time industrial data related to cell formation and practical implications such as job criticality and varying worker efficiencies in to consideration. Although the data collected from VCMS published literature reflect completely the real time environments, use of industry-specific data \& information in terms of jobs, workers and facilities and empirical aspects applicable to local industries will help realize the full benefits of this model. Therefore, an attempt will be made in future to include the real time data collected from local industries to train ANN and apply the results for a real time manufacturing environment.

On other hand, the potential improvements on proposed ANN approach are as follows: this model is currently applied to two cell configuration problems and could be extended to multi-cell configuration problems with suitable provisions for accommodating 
the extended training and testing data. Different class of ANNs such as radial basis functions (RBF) can be applied and a comparative study on its relative performance with that of MLP-FF could be taken up for any possible improvements in the results obtained.

\section{Acknowledgements}

The first author would like to place his gratitude and appreciation to Executives of Caledonian College of Engineering, Oman for continual support for his research work which this present study is a part of. Also he gratefully acknowledges the assistance of Mr.D.Ragavesh, Faculty, Electronic \& Computer Engineering Department, Caledonian College of Engineering, Oman, in successfully carrying out MATLAB tasks.

\section{References}

Askin, R. G., and Huang, Y., 2001. Forming effective worker teams for cellular manufacturing, International Journal of Production Research, Vol. 39, No.11, pp. 2431-2451.

Askin, R.G., and Huang, R. Y., 1997. Employee training and assignment for facility reconfiguration, Proc. 6th conf. on Industrial Engineering Research, Miami, FL, pp. 426-431.

Bopaya Bidanda, Poonsiri Ariyawongrat, Kim LaScola Needy, Bryan A. Norman \& Wipawee Tharmmaphornphilas., 2005. Human related issues in manufacturing cell design, implementation, and operation: a review and survey, Computers \& Industrial Engineering, Vol. 48, pp. 507-523.

Bryan, A. Norman, Wipaweetharmmaphornphilas, Kim Lascola Needy, Bopaya Bidanda and Rona Colosimo Warner., 2002. Worker assignment in cellular manufacturing considering technical and human skills, International Journal of Production Research, Vol. 40, No. 6, pp.1479-1492.

Dagli, C. and Huggahalli, R., A neural network approach to Group Technology, in J. Wang \& Y. Takefugi Ed., Neural Networks in Design and Manufacturing, (River Edge, NJ: World Scientific, 1993) 1-55.

Davis, D.J., Kher, H.V. and Wagner, B.J., 2009. Influence of workload imbalances on the need for worker flexibility, Computers \& Industrial Engineering, Vol. 57, pp.319-329.

Fowler, J.W., Wirojanagud, P. and Gel, E.S., 2008. Heuristics for workforce planning with worker differences, European Journal of Operational Research, Vol. 190, pp.724-740.

Haykin S., 'Neural Networks: A Comprehensive Foundation', Prentice-Hall, Englewood Cliffs, NJ, USA, 2nd edition, 1999.

James A. Freeman and David M Skapura, 'Neural Networks - Algorithms, Applications and Programming Techniques, International Student Edition, Addison Wesley, 1991, ISBN: 0-201-524449.

Jensen, J. B., 2000. The impact of resource flexibility and staffing decisions on cellular and departmental shop performance, European Journal of Operational Research, Vol. 127, pp. 279-296.

Jose' Fernando Goncalves, and Mauricio G.C. Resende., 2004. An evolutionary algorithm for manufacturing cell formation, Computers \& Industrial Engineering, Vol. 47, pp. 247-273.

Kannan, V. R., \& Jensen, J. B., 2004. Learning and labor assignment in a dual constrained cellular shop, International Journal of Production Research, Vol. 42, No.7, pp. 1455-1470.

Kannan, V.R. and Ghosh, S., 1996. A virtual cellular manufacturing approach to batch production, Decision Science, Vol. 27, pp. 519-539.

Kaparthi, S. and Suresh, N.C., 1992. Machine-component cell formation in group technology: a neural network approach, International Journal of Production Research, Vol. 30, No. 6, pp. 1353-1368.

MATLAB, The Language of Technical Computing, Neural Network Toolbox, The Mathworks Inc., 2007.

McDonald. T., Kimberly P. Ellis., Eileen M. Van Aken., and Patrick C. Koelling, 2009. Development and application of a worker assignment model to evaluate a lean manufacturing cell, International Journal of Production Research, Vol. 47, No. 9, pp. $2427-2447$.

Min, H., and Shin, D., 1993. Simultaneous formation of machine and human cells in group technology: A multiple objective approach, International Journal of Production Research, Vol. 31, pp. 2307-2318.

Murali, R.V., Prabhakaran, G., Puri, A.B. and Ragavesh, D., 2009. Worker efficiency and job criticality consideration in virtual cellular manufacturing environments, International Journal of Advanced Operations Management, Vol. 1, Nos. 2/3, pp. 203223.

Nomden, G., Slomp, J., and Suresh, N.C., 2006. Virtual manufacturing cells: a taxonomy of past research and identification of future research, International Journal of Flexible Manufacturing Systems, Vol. 17, pp.71-92.

Slomp, J., Chowdary, B.V. and Suresh, N.C., 2005-a. Design of virtual manufacturing cells: a mathematical programming approach, Robotics and Computer-Integrated Manufacturing, Vol. 21, pp. 273-288.

Slomp. J., Jos A.C. Bokhorst, and Eric Molleman, 2005-b. Cross-training in a cellular manufacturing environment, Computers and Industrial Engineering, Vol. 48, pp. 609-624. 
Sudhakara Pandian. R, and Mahapatra, S.S., 2009. Manufacturing cell formation with production data using neural networks, Computers \& Industrial Engineering, Vol. 56, No. 4, pp. 1340-1347.

Suer, G.A., 1996. Optimal operator assignment and cell loading in labor intensive manufacturing cells, Computers and Industrial Engineering, Vol. 31, No. 2, pp.155-158.

Suer, G.A., and Ivan Sánchez-Bera. 1997. Common cell size determination and cell loading in labor-intensive manufacturing cells, Computers \& Industrial Engineering, Vol. 33, No. 1-2, pp. 221-224.

Suer, G.A., and Ivan Sánchez-Bera., 1998. Optimal operator assignment and cell loading when lot-splitting is allowed', Computers and Industrial Engineering, Vol.35, No. 3-4, pp. 431-434.

Suresh, N. C., and Slomp, J., 2001. A multi-objective procedure for labour assignments and grouping in capacitated cell formation problems, International Journal of Production Research, Vol. 39, No. 18, pp. 4103-4131.

Suresh, N.C. and Slomp, J., 2005. Performance comparison of virtual cellular manufacturing with functional and cellular layouts in DRC settings, International Journal of Production Research, Vol. 43, No. 5, pp. 945-979.

Thompson, G.M., and Goodale, J.C., 2006. Variable employee productivity in workforce scheduling, European Journal of Operational Research, Vol. 170, pp.376-390.

Viviana I. Cesani', and Harold J. Steude, 2005. A study of labor assignment flexibility in cellular manufacturing systems, Computers and Industrial Engineering, Vol. 48, pp. 571-591.

Wemmerlov, U. and Johnson, D.J., 1997. Cellular manufacturing at 46 user plants: implementation experiences and performance improvements, International Journal of Operational Research, Vol. 35, pp. $29-49$.

\section{Biographical notes}

R. V. Murali is a Mechanical Engineering graduate working as Senior Faculty at Caledonian College of Engineering, Sultanate of Oman. He holds a master degree in Manufacturing Technology in the year 1996 from India. He is having 10 years of teaching and research experience, 2 years of software industry experience. He has 3 international journal papers, 4 international conference papers and 2 national level conference papers to his credit. He is currently pursuing his $\mathrm{PhD}$ programme in manufacturing engineering and his research expertise includes cellular manufacturing, virtual cellular manufacturing focusing on empirical aspects.

Dr. Asit Baran Puri graduated in Mechanical Engineering in 1990 from Regional Engineering College, Durgapur, India with first class (Honours). He completed his Master's Degree in Mechanical Engineering in 1992 from Jadavpur University, Kolkata, India. He has obtained his Ph.D degree from Jadavpur University, Kolkata, India in the year 2002. He has published 12 research papers in reputed International Journals, International and National conference proceedings as well. At present, he is Assistant Professor in the Department of Mechanical Engineering at National Institute of Technology, Durgapur in India.

Dr. G. Prabhakaran is a Senior Faculty in the Department of Mechanical Engineering \& Industrial Engineering at Caledonian College of Engineering, Sultanate of Oman. He has obtained his PhD degree from Regional Engineering College, Trichy, India in the year 2002. He is having nearly 19 years of teaching/research experience and published 26 international level journal papers, 4 national level journal papers, attended 7 international level and 25 national level conferences. His research expertise includes cellular manufacturing, virtual cellular manufacturing, tolerance design and analysis in mechanical assemblies.

Received January 2010

Accepted February 2010

Final acceptance in revised form March 2010 